\title{
Fatigue crack growth rate in ferrite-martensite dual-phase steel
}

\author{
R.Y. Deng and Z.J. Ye \\ Institute of Mechanics, Academia Sinica, Beïing, People's Republic of China
}

\begin{abstract}
An empirical study is made on the fatigue crack growth rate in ferrite-martensite dual-phase (FMDP) steel. Particular attention is given to the effect of ferrite content in the range of $24.2 \%$ to $41.5 \%$ where good fatigue resistance was found at $33.8 \%$. Variations in ferrite content did not affect the crack growth rate $\mathrm{d} a / \mathrm{d} N$ when plotted against the effective stress intensity factor range $\Delta K_{\text {eff }}$ which was assumed to follow a linear relation with the crack tip stress intensity factor range $\Delta K$. A high $\Delta K_{\mathrm{eff}}$ corresponds to uniformly distributed small size ferrite and martensite. No other appreciable correlation could be related to the microstructure morphology of the FMDP steel. The closure stress intensity factor $K_{\mathrm{cl}}$, however, is affected by the ferrite content with $K_{\mathrm{cl}} / K_{\text {max }}$ reaching a maximum value of 0.7 . In general, crack growth followed the interphase between the martensite and ferrite.

Dividing the fatigue crack growth process into Stage I and II where the former would be highly sensitive to changes in $\Delta K$ and the latter would increase with $\Delta K$ depending on the $R=\sigma_{\min } / \sigma_{\max }$ ratio. The same data when correlated with the strain energy density factor range $\Delta S$ showed negligible dependence on mean stress or $R$ ratio for Stage I crack growth. A parameter $\alpha$ involving the ratio of ultimate stress to yield stress, percent reduction of area and $R$ is introduced for Stage II crack growth so that the $\mathrm{d} a / \mathrm{d} N$ data for different $R$ would collapse onto a single curve with a narrow scatter band when plotted against $\alpha \Delta S$.
\end{abstract}

\section{Introduction}

Improved strength and ductility can create a two-phase microstructure in steel. This can be achieved by appropriate heat treatment [1-4]. Under repeated stresses, microscopic plasticity introduces nonhomogeneity in the dual-phase steel on account of the dissimilar physical/ mechanical properties of the martensite and ferrite in addition to their size and distribution. These effects are reflected through the fatigue crack growth data which are analyzed in this work as the ferrite content and mean stress level are varied.

The data are generally represented by plots of $\mathrm{d} a / \mathrm{d} N$ against $\Delta K$. Better correlation can be obtained by using the strain energy density factor range $\Delta S[5,6]$ that accounts for the mean stress effect. An empirical parameter $\alpha$ suggested in $[7,8]$ is also used as a correction on $\Delta S$ or $\alpha \Delta S$ for representing crack growth rate data.

\section{Description of heat treatment and fatigue tests}

Special heat treatments are administered to create different ferrite contents in specimens which are notched for initiating cracks under cyclic loading. Crack propagation data are then taken by varying the mean stress level of the constant amplitude loading.

\subsection{Heat treatment}

Two types of heat treatments are given to the $16 \mathrm{MnR}$ steel in rolled condition with $16 \mathrm{~mm}$ thickness so that the ferrite content and microstructure could be varied. The first set of specimens were heated at $780^{\circ} \mathrm{C}, 810^{\circ} \mathrm{C}$ and $850^{\circ} \mathrm{C}$ in the two phase region; they are then quenched in brine and tempered at $200{ }^{\circ} \mathrm{C}$. This batch is referred to A-1, A-2 and A-3 with the corresponding mechanical properties given in Table 1. Note that the martensite microhardness tends to reduce with the heat treatment temperature. The second batch labelled as B-1, B-2 and B-3 in Table 1 were heated at $1200^{\circ} \mathrm{C}$ for diffuse annealing. They were subsequently heated at $930^{\circ} \mathrm{C}$ and then cooled in brine, air and furnace. All of them were heated again to $810^{\circ} \mathrm{C}$ followed by quenching in brine and tempering at $200^{\circ} \mathrm{C}$. Shown in Figs. 1(a), 1(b) and 1(c) are, respectively, the microstructure of specimens B-1, B-2 

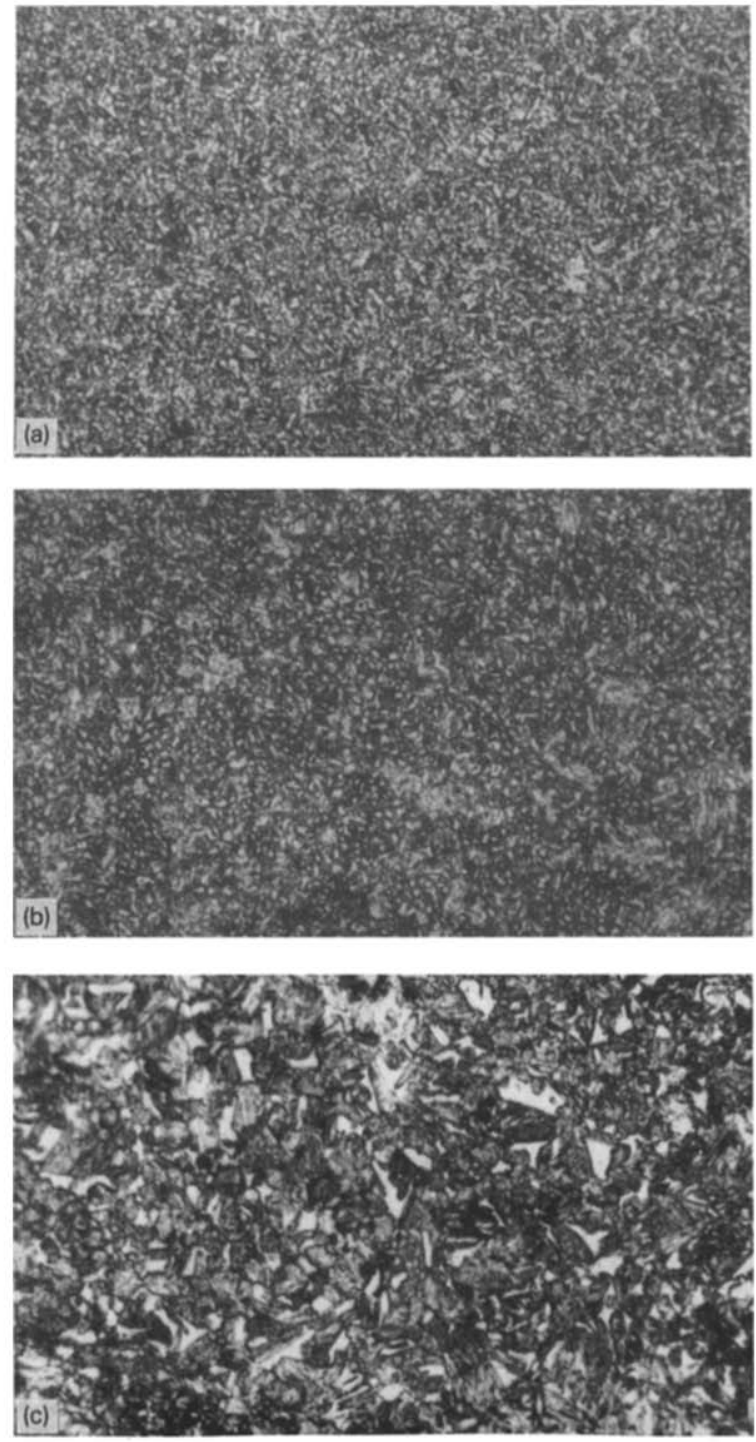

Fig. 1. Microstructure $(200 \times)$ of dual-phase steel with ditterent heat treatments; specimens (a) B-1; (b) B-2; and (c) B-3.

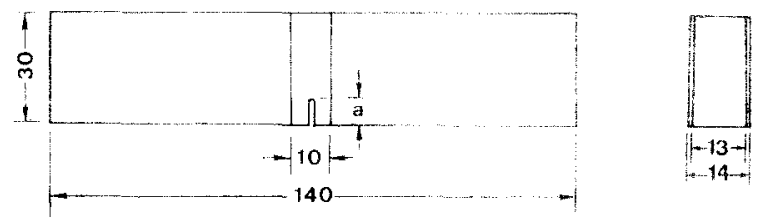

Fig, 2. Schematic of FMDP steel notched specimen (dimen. sions in $\mathrm{mm}$ ?

and B-3 magnified 200 times. Increase in the coarseness of the microstructure is clearly shown. The ferrite contents were measured by application of Quantiment 520 phase analysis equipment.

\subsection{Specimen configuration and load}

The dimensions of the test specimen are 140 $\mathrm{mm} \times 30 \mathrm{~mm} \times 13 \mathrm{~mm}$ as shown in Fig. 2. It contains an initial notch of length $a$ at the center and is subjected to three-point bending repeated cyclically at constant amplitudes of $\Delta P=700 \mathrm{kgf}$ and $910 \mathrm{kgf}$ with a frequency of $90 \mathrm{~Hz}$ under room temperature condition. Two values of $R=$ $\sigma_{\min } / \sigma_{\text {max }}=0.3$ and 0.7 are used

\subsection{Crack initiation}

During the early stage of cyclic loading with $R=0.3$, slip lines appeared near the notch and they gradually develop into microcracks as the load cycles are increased. Figure 3 shows that most of the microcracks initiated at the interphase between the ferrite and martensite. The microcracks grew progressively and coalesced to form a main crack when $\Delta P=700 \mathrm{kgf}$. At $\Delta P=$ $910 \mathrm{kgf}$, several microcracks developed near the

Table 1

Mechanical properties of ferrite-martensite steel

\begin{tabular}{|c|c|c|c|c|c|c|c|c|}
\hline $\begin{array}{l}\text { Specimen } \\
\text { type }\end{array}$ & $\begin{array}{l}\text { Young's } \\
\text { modulus } \\
E \times 10^{5}(\mathrm{MPa})\end{array}$ & $\begin{array}{l}\text { Hardening } \\
\text { exponent } \\
n\end{array}$ & $\begin{array}{l}\text { Elongation } \\
\%\end{array}$ & $\begin{array}{l}\text { Reduction } \\
\text { in area } \\
y\end{array}$ & $\begin{array}{l}\text { Yield } \\
\text { stress } \\
(0.2 \% \text { oftset }) \\
\sigma_{\mathrm{ys}}(\mathrm{MPa})\end{array}$ & $\begin{array}{l}\text { Ultimale } \\
\text { stress } \\
\sigma_{\mathrm{s}}(\mathrm{MPa})\end{array}$ & $\begin{array}{l}\text { Ferrite } \\
\text { content } \\
\end{array}$ & $\begin{array}{l}\text { Martensite } \\
\text { micro- } \\
\text { hardness } \\
\text { HV }\end{array}$ \\
\hline As rolled & 2.48 & 0.17 & 16.7 & 68.7 & 367 & 545 & $\cdots$ & - \\
\hline A-1 & 1.82 & 0.12 & 10.3 & 43.1 & 603 & 930 & $4 \div$ & 342 \\
\hline A-2 & 1.52 & 0.09 & 11.2 & 44.9 & 720 & 984 & $B s$ & 241 \\
\hline A-3 & 1.94 & 0.08 & 7.9 & 42.5 & 755 & 1021 & 24.2 & 196 \\
\hline B-1 & 2.05 & 0.11 & 14.4 & 46.1 & 692 & 960 & 20,3 & 229 \\
\hline B-2 & 2.07 & 0.12 & 14.2 & 46.7 & 542 & 880 & 32.7 & 262 \\
\hline B-3 & 2.00 & 0.14 & 15.1 & 47.5 & 535 & 877 & 38 & 252 \\
\hline
\end{tabular}




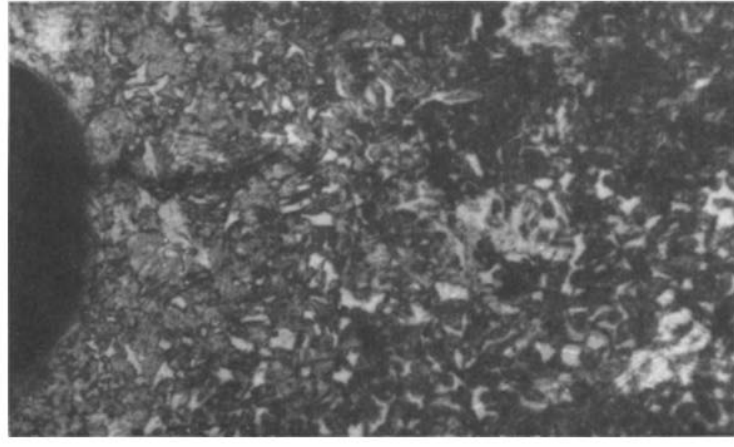

Fig. 3. Microcracks initiated at interphase of ferrite and martensite $(200 \times)$.

notch about the same time. As they reached a length of approximately 0.3 to $0.6 \mathrm{~mm}$, the leading one would take off while the others remain behind. The crack initiation life $N_{0}$ for the FMDP steel is larger than the $16 \mathrm{MnR}$ steel in its rolled state. The largest initiation life was obtained for specimen B-1 corresponding to a dual-phase steel heated at $930^{\circ} \mathrm{C}$ and then cooled in brine. Increase in $N_{0}$ is about an order of magnitude more than the $16 \mathrm{MnR}$ rolled steel. The results are summarized in Table 2.

\section{Correlation of crack growth rate}

Fatigue crack growth data are usually presented by plotting the rate $\mathrm{d} a / \mathrm{d} N$ as a function of a parameter that represents the range of the local stress intensity or equivalent quantity. One of the quantities to be considered is the threshold stress intensity range $\Delta K_{\mathrm{th}}$ corresponding to $10^{6}$

Table 2

Crack initiation life

\begin{tabular}{lcl}
$\begin{array}{l}\text { Specimen } \\
\text { type }\end{array}$ & \multicolumn{2}{l}{$\begin{array}{l}\text { Initiation life } \\
N_{0} \times 10^{5} \text { (cycles) }\end{array}$} \\
\cline { 2 - 3 } & $\Delta P=700 \mathrm{kgf}$ & $\Delta P=910 \mathrm{kgf}$ \\
\hline As rolled & 1.10 & 0.43 \\
A-1 & 4.23 & 1.22 \\
A-2 & 6.69 & 3.74 \\
A-3 & 5.99 & 2.98 \\
B-1 & 71.80 & 4.86 \\
B-2 & 24.80 & 4.28 \\
B-3 & 22.51 & 3.92 \\
\hline
\end{tabular}

Table 3

Stress intensity factor: threshold and closure

\begin{tabular}{lcll}
\hline $\begin{array}{l}\text { Specimen } \\
\text { type }\end{array}$ & \multicolumn{2}{l}{$\begin{array}{l}\text { Threshold } \\
\Delta K_{\mathrm{th}}(\mathrm{MPa} \sqrt{\mathrm{m}})\end{array}$} & $\begin{array}{l}\text { Closure } \\
K_{\mathrm{cl}}(\mathrm{MPa} \sqrt{\mathrm{m}})\end{array}$ \\
\hline \multicolumn{3}{l}{$R=0.3$} & $R=0.7$ \\
\hline As rolled & 6.85 & 4.20 & 5.37 \\
A-1 & 7.90 & 4.73 & 6.60 \\
$\mathrm{~A}-2$ & 8.97 & 3.92 & 8.93 \\
A-3 & 8.34 & 4.20 & 7.72 \\
B-1 & 10.30 & 6.60 & 8.1 \\
B-2 & 9.41 & 5.51 & 7.9 \\
B-3 & 9.25 & 5.45 & 8.1 \\
\hline
\end{tabular}

cycles of loading with a crack growth increment of not more than $0.1 \mathrm{~mm}$; it is defined as

$\Delta K_{\mathrm{eff}}=K_{\max }-K_{\mathrm{cl}}$

where $K_{\mathrm{cl}}$ is crack closure stress intensity factor $[9,10]$. Shown in Table 3 are values of $\Delta K_{\text {th }}$ and $K_{\text {cl }}$ for the different specimens. For $R=0.3$, the highest and lowest $\Delta K_{\mathrm{th}}$ correspond, respectively, to specimen B-1 with $29.5 \%$ ferrite and A-1 with $41.5 \%$ ferrite. Variations of $\Delta K_{\mathrm{th}}$ with ferrite content are not as pronounced for $\mathrm{R}=0.7$.

\subsection{Stress intensity factor range}

Plotted in Fig. 4(a) are $\log \mathrm{d} a / \mathrm{d} N$ versus $\log \Delta K$ for $R=0.3$ where four different values of $\Delta K_{\text {th }}$ are obtained as given in Table 3. A slight variation in $\Delta K$ would yield large changes in $\mathrm{d} a / \mathrm{d} N$. The values of $\Delta K_{\mathrm{th}}$ were measured by using load decrease by degrees with $\Delta K$ value. This regime is referred to as Stage I crack propagation. Application of eq. (1) and the formula

$$
\frac{\mathrm{d} a}{\mathrm{~d} N}=4.2141 \times 10^{-17}\left(\Delta K_{\mathrm{eff}}\right)^{9.11026}
$$

The same data could be represented by a single curve with a correlation coefficient of 0.9315 as shown in Fig. 4(b). Corrections for the crack closure effect tends to increase with decreasing $\Delta K$. They are shown in Fig. 5 and are in agreement with the results in [11-13]. A maximum of $K_{\mathrm{cl}} / K_{\max }=0.7$ is obtained for the A-2 specimen with $33.8 \%$ ferrite which has the lowest crack growth rate, Fig. 4(a). Similarly, the $\Delta K_{\text {th }}$ values for specimens B-1, B-2 and B-3 in Table 3 for $R=0.3$ and 0.7 can be obtained by decreasing the applied load amplitude. The stage I crack propa- 

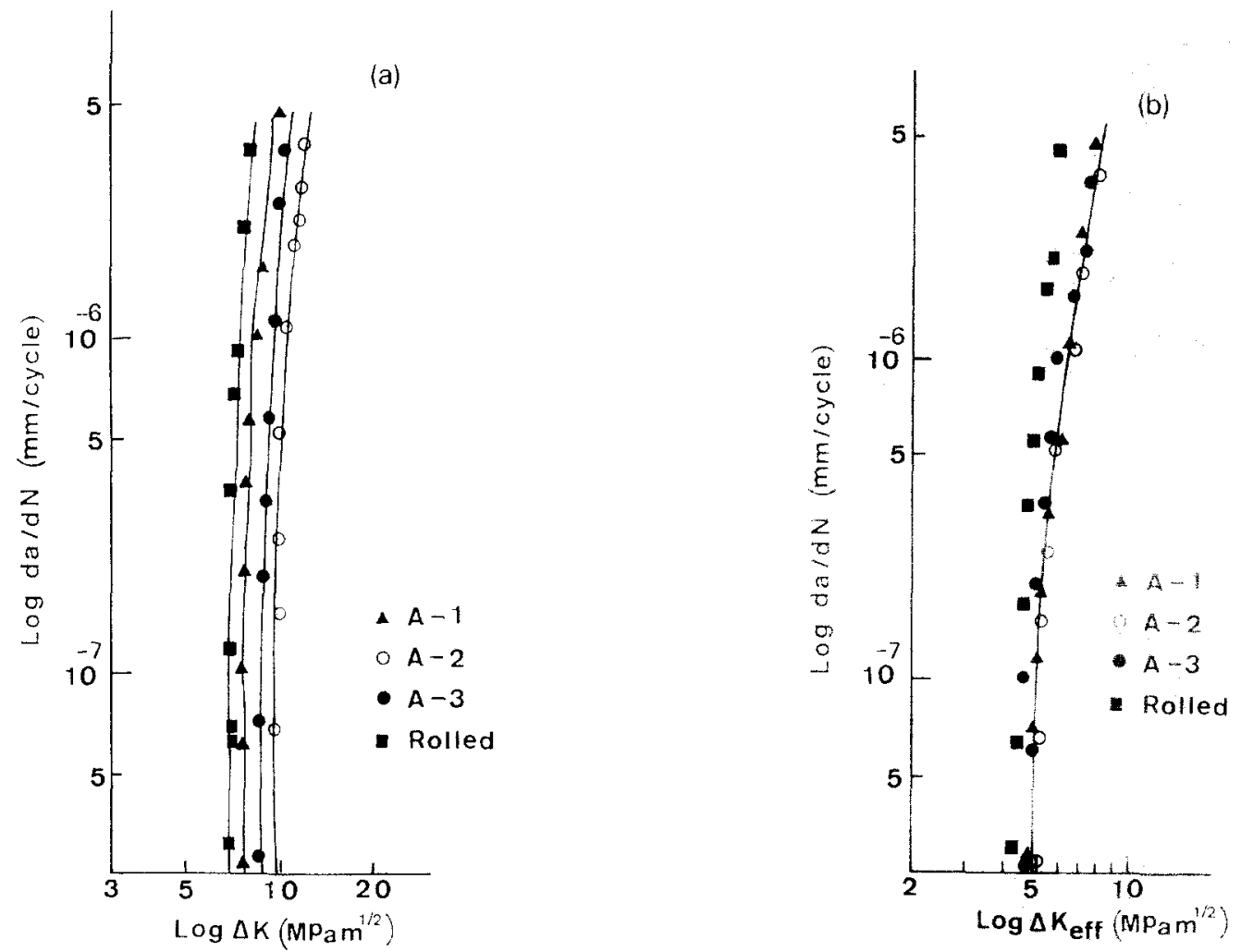

Fig. 4. Stage I crack propagation near threshold at $R=0.3$ for specimens $A-1, A-2$ and $A-3$.

gation is shown, respectively, in Figs. 6(a) and 6(b) on plots of $\mathrm{d} a / \mathrm{d} N$ versus $\Delta K$. The data scatter, however, did not improve when $\Delta K_{\text {eff }}$ is used instead of $\Delta K$. This is shown in Fig. 6(c) for

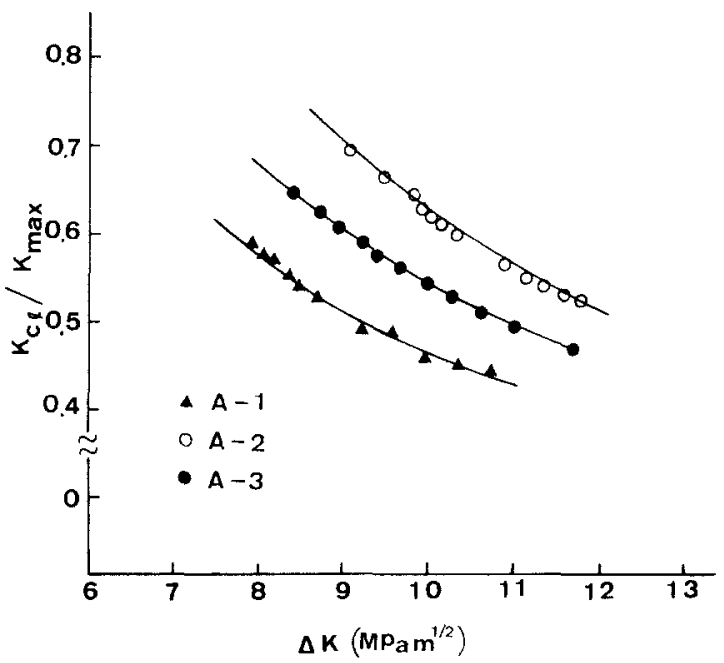

Fig. 5. Normalized Stage I crack closure intensity factor versus crack tip intensity range for specimens A-1, A-2 and A-3 with $R=0.3$.
$\mathrm{R}=0.3$. Largest $\left(\Delta K_{\text {eff }}\right)_{\text {th }}$ value corresponds to specimen B-1 while $K_{\mathrm{cl}}$ remains unchanged for the three cases. A straight line relationship is obtained in Fig. 7 when $\Delta K$ ett is plotted against $\Delta K$ :

$\Delta K_{\mathrm{eff}}=-27.8512+1.4783 \Delta K$

The correlation coefficient is 0.9898 .

Generally speaking, at a given $\Delta K$ level, a lower $\Delta K_{\text {th }}$ would correspond to higher crack growth as shown by the data in Figs. 6(a)-6(c). This is consistent with the results in Fig. 8 that plots $K_{\mathrm{cl}} / K_{\max }$ against $\Delta K$ because

$\Delta K=K_{\max }(1-R)$

where $R=\sigma_{\min } / \sigma_{\max }$. Applying eq. (1) to the condition at threshold, there results

$\left(K_{\max }\right)_{\mathrm{th}}=K_{\mathrm{cl}}+\left(\Delta K_{\mathrm{eff}}\right)_{\mathrm{th}}$

Because $\left(\Delta K_{\text {eff }}\right)_{\text {th }}$ is largest for B-1 in Fig. 6(c), the same holds for $\left(K_{\text {max }}\right)_{\text {th }}$ from eq. (5) as $K_{\mathrm{cl}}$ does not change. The ratio $K_{\mathrm{cl}} / K_{\max }$ would therefore be the smallest for B-1 as shown in Fig. 8 . It is change in the microstructure of the dual- 
phase steel that alters the deviations in crack growth characteristics. Crack closure has been attributed to fracture surface roughness [14] at room temperature and to the austenite grain size $[15,16]$. These, however, are only qualitative observations. How does crack closure affect crack
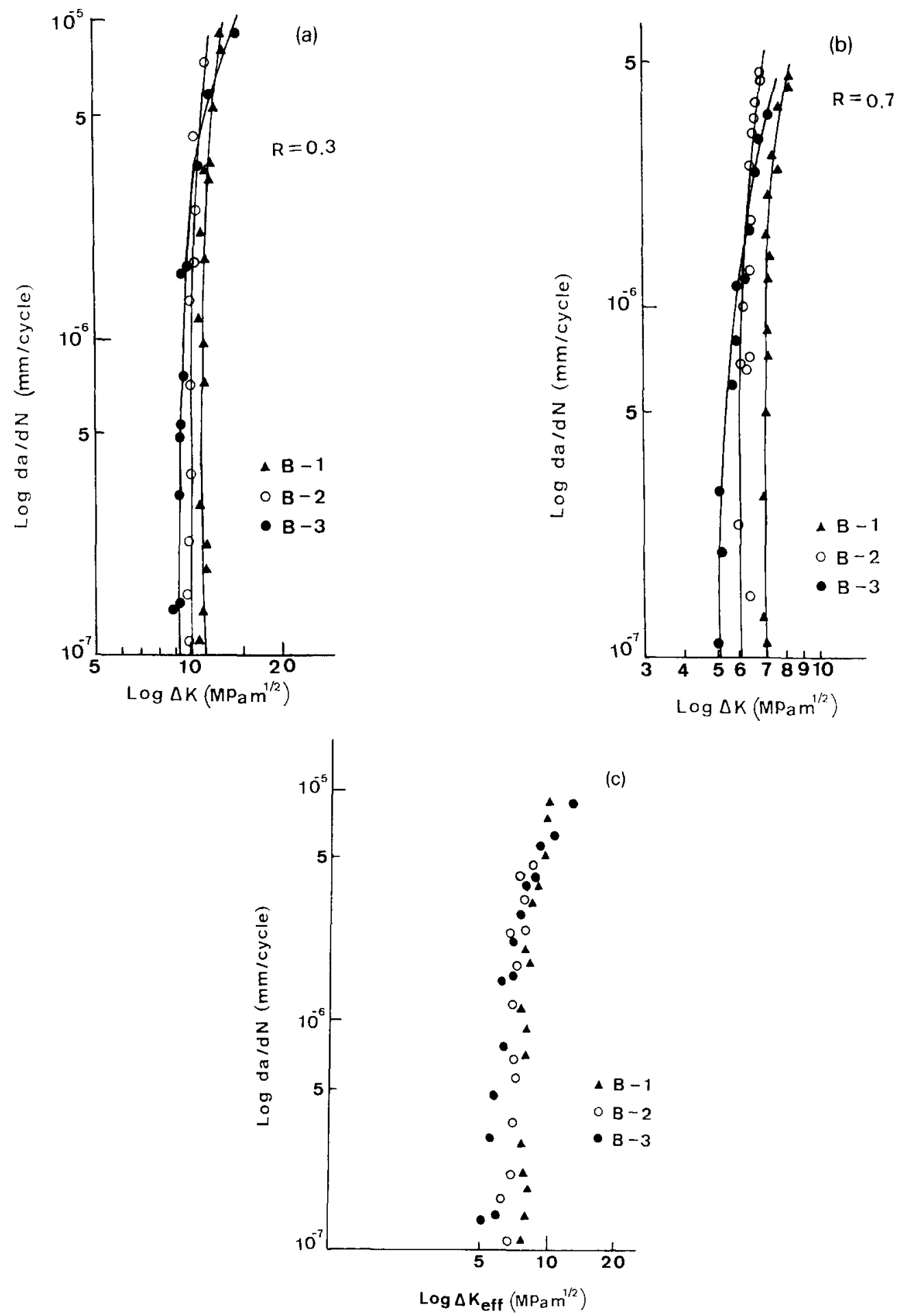

Fig. 6. Stage I crack propagation near threshold for specimens B-1, B-2 and B-3, 


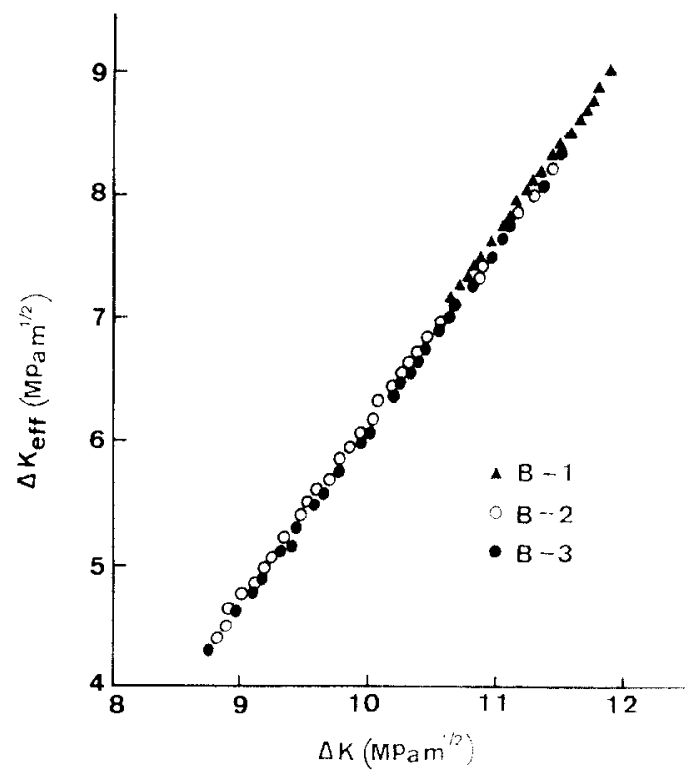

Fig. 7. Stage I effective versus crack tip stress intensity factor range for specimens $\mathrm{B}-1, \mathrm{~B}-2$ and $\mathrm{B}-3$ with $R=0.3$.

growth retardation is still not very clear. Recent work has shown that the crack opening displacement and closure do not correlate well [17] with observed fatigue damage data. No conclusive remarks could be made from the empirical approach except to show that the influence of material microstructure on crack growth.

Stage II crack growth data for specimens B-1. B-2 and B-3 are shown in Fig. 9(a) for $R=0.3$ and Fig. 9(b) for $R=0.7$. Deviations among the

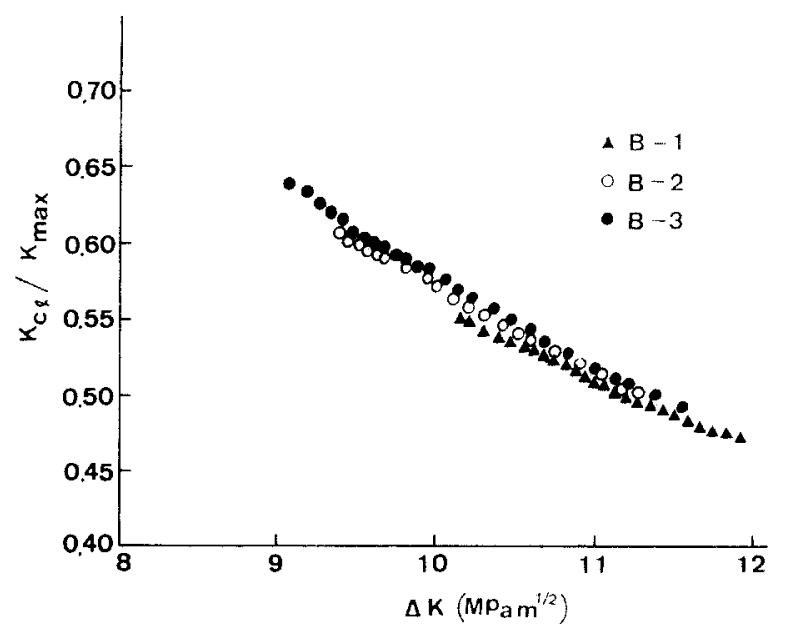

Fig. 8. Normalized Stage I crack closure stress intensity factor versus crack tip stress intensity factor range for specimens $\mathrm{B}-1, \mathrm{~B}-2$ and $\mathrm{B}-3$ with $R=0.3$.

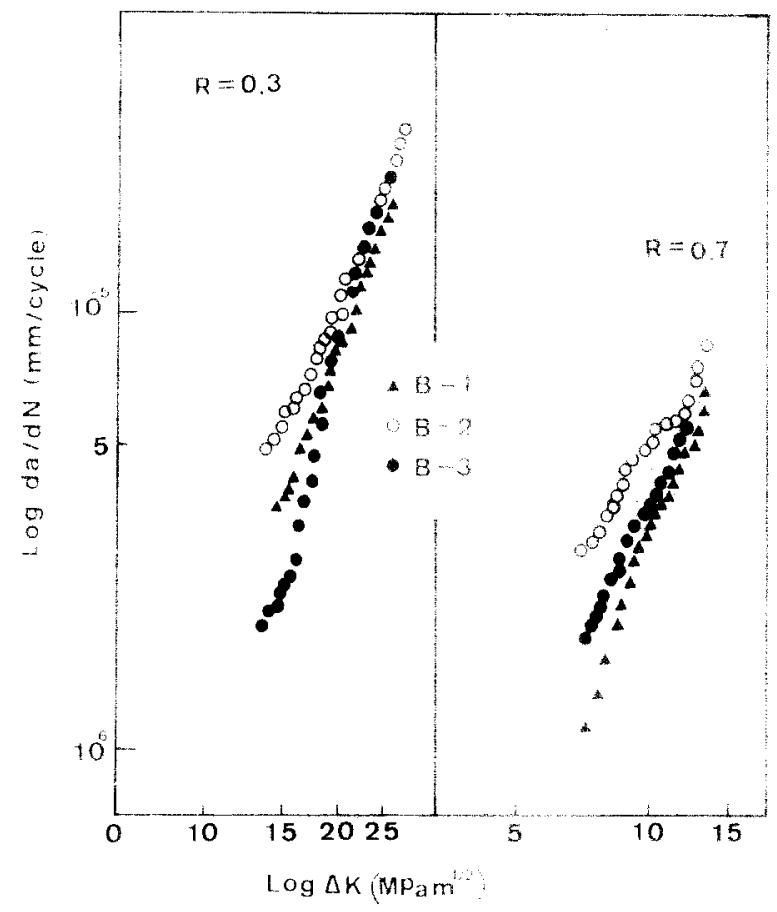

Fig. 9. Stage Il crack growth rate for specimens B-1, B-2 and $\mathrm{B}-3$ with $R=0.3$ and 0.7

curves due to differences in material microstructure are large for low $\Delta K$ but they tend to diminish at $\Delta K=22 \mathrm{MPa} \sqrt{\mathrm{m}}$ for $R=0.3$ and $\Delta K=11.8 \mathrm{MPa} \sqrt{\mathrm{m}}$ for $R=0.7$

\subsection{Strain energy density factor range}

One of the obvious deficiencies of $\mathrm{d} a / \mathrm{d} N$ versus $J K$ plots is that the mean stress level is not accounted for. Data would tend to scatter as different $R$ ratios are used. The strain energy density factor range $\Delta S[5-8]$ includes the mean stress effect and yields better correlation with fatigue data. Proposed in $[7,8]$ were a way to best fit the fatigue data by assuming that $\mathrm{d} a / \mathrm{d} N$ is a function of $\Delta S$ or $\alpha \Delta S$ :

$$
\frac{\mathrm{d} a}{\mathrm{~d} N}=f(\Delta S) \text { or } f(\alpha \Delta S)
$$

A regression technique was developed to best fit the experimental data. In eq. (6), $\alpha$ is a parameter given by

$\alpha=\frac{1+R}{1+R \beta^{2}}$ 
in which

$\beta=\frac{\sigma_{\mathrm{ul}}}{\sigma_{\mathrm{ys}}}(1+\% \mathrm{RA})$

Values of $\sigma_{\mathrm{ul}}, \sigma_{\mathrm{ys}}$ and $\%$ RA for the FMDP steel specimens are given in Table 1. According to the strain energy density criterion $[5,6]$, the strain energy density factor range is given by

$\Delta S=S_{\max }-S_{\min }$

For a Mode I crack problem, $\Delta S$ can be written as

$\Delta S=\frac{(1+\nu)(1-2 \nu)}{2 \pi E}\left(\frac{1+R}{1-R}\right) \Delta K^{2}$

with $\nu=0.3$ for steel and $E$ can be found in Table 1. Without going into details, the same

Table 4

Crack growth data for specimens B-1, B-2 and B-3 with $R=0.3$

\begin{tabular}{|c|c|c|c|c|c|}
\hline \multicolumn{2}{|c|}{ Specimen B-1 } & \multicolumn{2}{|c|}{ Specimen B-2 } & \multicolumn{2}{|c|}{ Specimen B-3 } \\
\hline $\begin{array}{l}a \\
(\mathrm{~mm})\end{array}$ & $\begin{array}{l}N \\
\times 10^{3} \\
\text { (cycle) }\end{array}$ & $\begin{array}{l}a \\
(\mathrm{~mm})\end{array}$ & $\begin{array}{l}N \\
\times 10^{3} \\
\text { (cycle) }\end{array}$ & $\begin{array}{l}a \\
(\mathrm{~mm})\end{array}$ & $\begin{array}{l}N \\
\times 10^{3} \\
\text { (cycle) }\end{array}$ \\
\hline 7.97 & 196,274 & 8.00 & 197,279 & 8.05 & 198,794 \\
\hline 8.27 & 196,317 & 8.30 & 197,315 & 8.25 & 198,865 \\
\hline 8.57 & 196,354 & 8.60 & 197,347 & 8.55 & 198,976 \\
\hline 8.87 & 196,400 & 8.90 & 197,389 & 8.88 & 199,117 \\
\hline 9.17 & 196,457 & 9.20 & 197,430 & 9.05 & 199,242 \\
\hline 9.47 & 196,520 & 9.50 & 197,477 & 9.25 & 199,327 \\
\hline 9.77 & 196,583 & 9.80 & 197,524 & 9.45 & 199.402 \\
\hline 10.07 & 196,645 & 10.10 & 197,571 & 9.65 & 199.483 \\
\hline 10.37 & 196,705 & 10.40 & 197,610 & 9.85 & 199,557 \\
\hline 10.67 & 196,758 & 10.73 & 197,659 & 10.08 & 199,622 \\
\hline 10.97 & 196,810 & 11.04 & 197,695 & 10.25 & 199.673 \\
\hline 11.27 & 196,869 & 11.30 & 197,727 & 10.45 & 199.726 \\
\hline 11.57 & 196,903 & 11.60 & 197,760 & 10.65 & 199.777 \\
\hline 11.87 & 196,941 & 11.90 & 197,791 & 10.85 & 199.816 \\
\hline 12.17 & 196,973 & 12.20 & 197,819 & 11.05 & 199,862 \\
\hline 12.47 & 197.004 & 12.50 & 197,845 & 11.40 & 199,914 \\
\hline 12.82 & 197,035 & 12.80 & 197,868 & 11.73 & 199,967 \\
\hline 13.17 & 197,064 & 13.10 & 197,895 & 11.95 & 199,998 \\
\hline 13.47 & 197,088 & 13.40 & 197,915 & 12.25 & 200,937 \\
\hline 13.77 & 197.113 & 13.70 & 197,937 & 12.65 & 200,074 \\
\hline 14.09 & 197,149 & 14.00 & 197,958 & 12.85 & 200,091 \\
\hline 14.37 & 197,174 & 14.30 & 197,976 & 13.18 & 200,119 \\
\hline \multirow[t]{6}{*}{14.67} & 197,192 & 14.63 & 198,000 & 13.45 & 200,138 \\
\hline & & 14.90 & 198,011 & 13.75 & 200,157 \\
\hline & & 15.20 & 198,025 & 14.05 & 200,177 \\
\hline & & 15.50 & 198,040 & 14.35 & 200,195 \\
\hline & & & & 14.65 & 200,213 \\
\hline & & & & 14.95 & 200,248 \\
\hline
\end{tabular}

Table 5

Crack growth data for specimens B-1, B-2 and B-3 with $\mathrm{R}=0.7$

\begin{tabular}{|c|c|c|c|c|c|}
\hline \multicolumn{2}{|c|}{ Specimen B-1 } & \multicolumn{2}{|c|}{ Specimen B-2 } & \multicolumn{2}{|c|}{ Specimen B-3 } \\
\hline $\begin{array}{l}a \\
(\mathrm{~mm})\end{array}$ & $\begin{array}{l}N \\
\times 10^{3} \\
\text { (cycle) }\end{array}$ & $\begin{array}{l}a \\
(\mathrm{~mm})\end{array}$ & $\begin{array}{l}N \\
\times 10^{3} \\
\text { (cycle) }\end{array}$ & $\begin{array}{l}a \\
(\mathrm{~mm})\end{array}$ & $\begin{array}{l}N \\
\times 10^{3} \\
\text { (cycle) }\end{array}$ \\
\hline 8.93 & 200.267 & 8.00 & 202.715 & 7.54 & 204,229 \\
\hline 9.13 & 200,465 & 8.30 & 202,727 & 7.65 & 204,350 \\
\hline 9.33 & 200,733 & 8.60 & 202,760 & 7.89 & 204,463 \\
\hline 9.56 & 201.005 & 8.90 & 202,785 & 8.05 & 204,585 \\
\hline 9.73 & 201,212 & 9.20 & 202,868 & 8.25 & 204,689 \\
\hline 10.10 & 201,327 & 9.50 & 202,934 & 8.55 & 204,835 \\
\hline 10.46 & 201,419 & 9.80 & 203,008 & 8.95 & 204,993 \\
\hline 10.76 & 201.512 & 10.10 & 203,080 & 9.25 & 205,105 \\
\hline 11.36 & 201.767 & 10.40 & 203,160 & 9.55 & 205,210 \\
\hline 11.66 & 201,836 & 10.70 & 203,222 & 9.85 & 205,359 \\
\hline 11.96 & 201,921 & 11.00 & 203,291 & 10.15 & 205,479 \\
\hline 12.26 & 202,012 & 11.30 & 203,361 & 10.45 & 205,595 \\
\hline 12.56 & 202,098 & 11.70 & 203,420 & 10.75 & 205,714 \\
\hline 12.86 & 202,173 & 12.00 & 203,480 & 11.05 & 205,818 \\
\hline 13.16 & 202,253 & 12.30 & 203,530 & 11.35 & 205,912 \\
\hline 13.46 & 202,336 & 12.60 & 203,597 & 11.65 & 206,0007 \\
\hline 13.76 & 202,402 & 12.90 & 203,662 & 11.95 & 206.095 \\
\hline 14.06 & 202,467 & 13.20 & 203,720 & 12.25 & 206,183 \\
\hline 14.36 & 202,521 & 13.50 & 203,790 & 12.55 & 206,260 \\
\hline 14.56 & 202,587 & 13.80 & 203,855 & 12.85 & 206,324 \\
\hline 14.86 & 202,635 & 14.20 & 203,919 & 13.18 & 206,401 \\
\hline \multirow[t]{3}{*}{15.16} & 202,685 & 14.60 & 203,978 & 13.45 & 206,457 \\
\hline & & 15.00 & 204,035 & 13.75 & 206,513 \\
\hline & & & & 14.05 & 206,571 \\
\hline
\end{tabular}

fatigue data as given in Tables 4 and 5 will be presented using $\Delta S$ and compared to those using $\Delta K$ for the specimens $\mathrm{B}-1, \mathrm{~B}-2$ and $\mathrm{B}-3$ with $\mathrm{R}=0.3$ and 0.7 .

Stage I. Exhibited in Figs. 10(a), 11(a) and 12(a) would be crack growth rate plots using $\Delta K$ while those in Figs. 10(b), 11(b) and 12(b) would be based on $\Delta S$ for the Stage I regime where the cracks grow relatively slow. The general trends of the curves for specimens B-1, B-2 and B-3 are similar where the data scatter caused by the difference in $\mathrm{R}=0.3$ and 0.7 is significant when using $\Delta K$ and diminishes when using $\Delta S$. This observation was also made in [6] for other metal alloys.

Stage II. Even better correlation is obtained if $\alpha$ in eq. (7) is included [7,8]. Particularly noticeable is the data in Figs. 13(a) and 13(b) for the B-1 specimen. The two curves based on $\Delta K$ in Fig. 13(a) merged into one when they are represented 
by $\alpha \Delta S$ in Fig. 13(b). Similar tendencies can be seen from the results in Figs. 14(a) and 14(b) for specimen B-2 and Figs. 15(a) and 15(b) for specimen B-3.

\section{Ductility and crack path}

A phase contact microscope is used to observe the distorted zone in linear dimension of $\omega$ next to the main crack surface. This is shown in Fig. 16 where the slip bands appear as wavy lines and microcracks around the main crack show up as darker lines. Measurements are taken at thresh- old and Stage II crack growth in terms of the parameter

$\Omega=\frac{\omega}{\left(K_{\max } / \sigma_{y s}\right)^{2}}$

Their values are summarized in Table 6 for $R=$ 0.3 and 0.7 where $\Omega_{\text {th }}$ stands for $\Omega$ at the threshold condition. A large $\Omega$ corresponds to more distortion of the material around the crack which would presumably translate to more plastic deformation or ductility. It increases with the ferrite content that is assumed to have plastic flow. Table 6 also shows that $\Omega_{\mathrm{th}}$ or $\Omega$ decreases with increasing $R$ as it would be expected on physical ground.
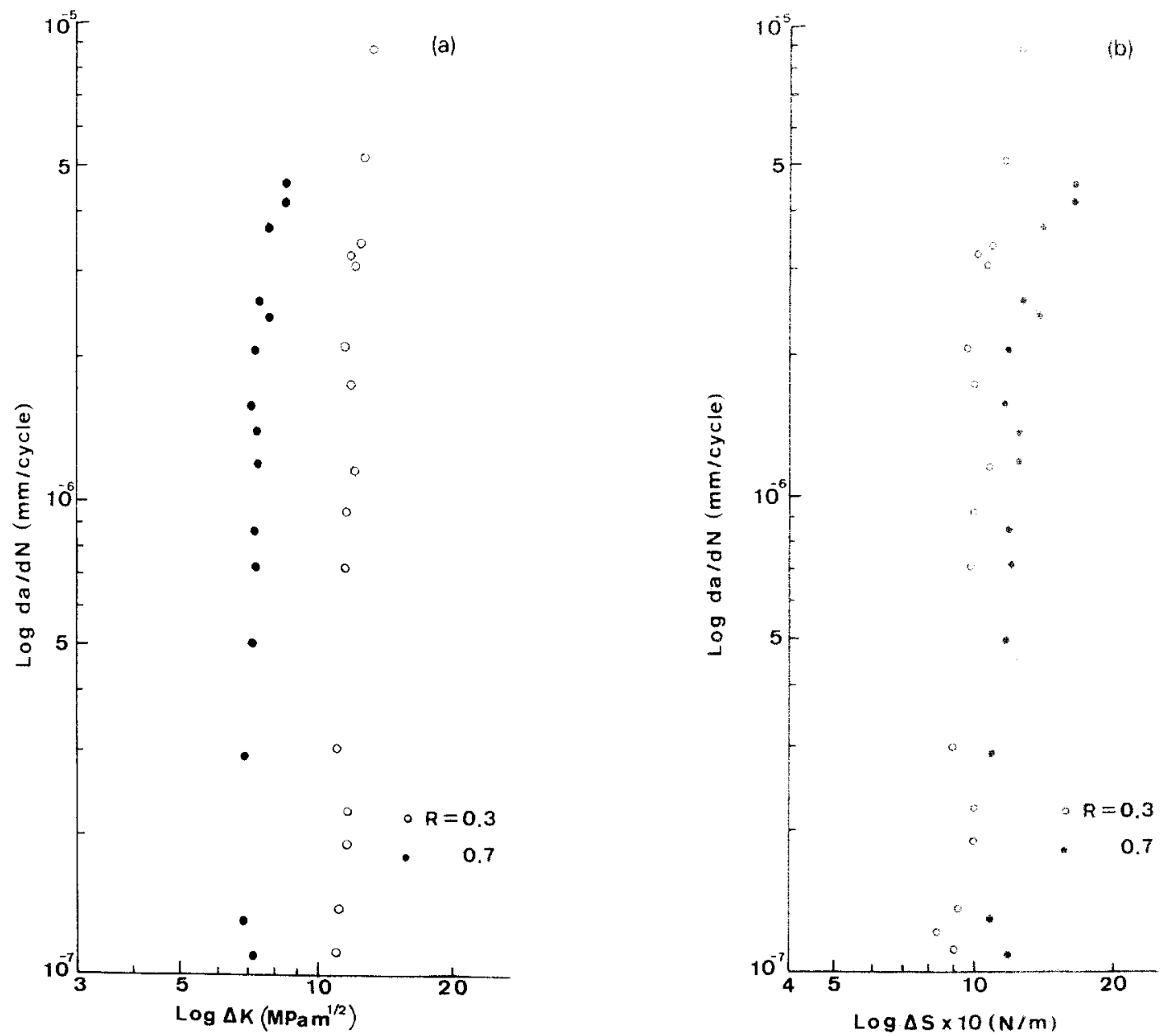

Fig. 10. Stage I crack growth rate against $\Delta K$ and $\Delta S$ for B-1 specimen with $R=0.3$ and 0.7 

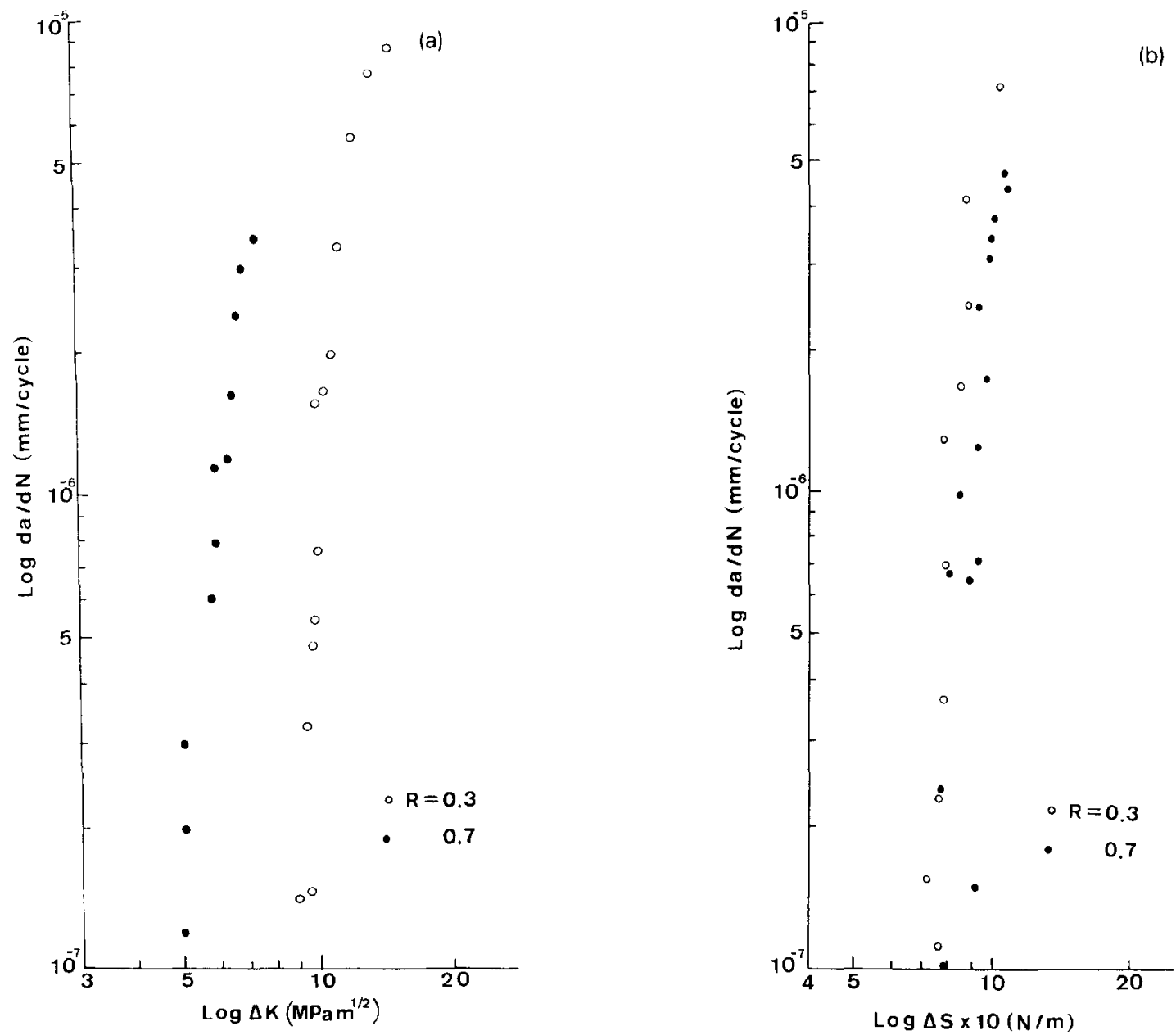

Fig. 11. Stage I crack growth rate against $\Delta K$ and $\Delta S$ for B-2 specimen with $R=0.3$ and 0.7 .

Electron microphoto in Fig. 17 shows that main crack follows the interphase boundary between the ferrite and martensite. The fracture surface is predominantly quasi-cleavage appearing as martensite platelets while cleavage corresponds to the ferrite shown in the square region identified in Fig. 18 by an arrow. Observed at threshold are small facets about the size of the original austenite grains and parallel striations on the cleavage plateau.

\section{Conclusions}

Appropriate heat treatment can be applied to the $16 \mathrm{MnR}$ steel to introduce ferrite and martensite making the steel a two-phase material that would yield high strength, good ductility and better resistance to fatigue. Based on the empiri- cal study, the following conclusions could be made:

- Two sets of specimens were made subjecting them to different heat treatments. The specimen labelled as B-1 was superior to others.

- Ferrite contents were found to affect the crack growth rates correlated in terms of stress intensity factor ranges identified with threshold and crack closure.

- The strain energy density factor range gave better correlation than the stress intensity factor range where data for different mean stresses collapsed into a single curve where the scatter is limited.

- Local distortion of the material next to the main crack could be measured and introduced into an empirical parameter. It can be used to rank the material ductility as other physical parameters are varied. 


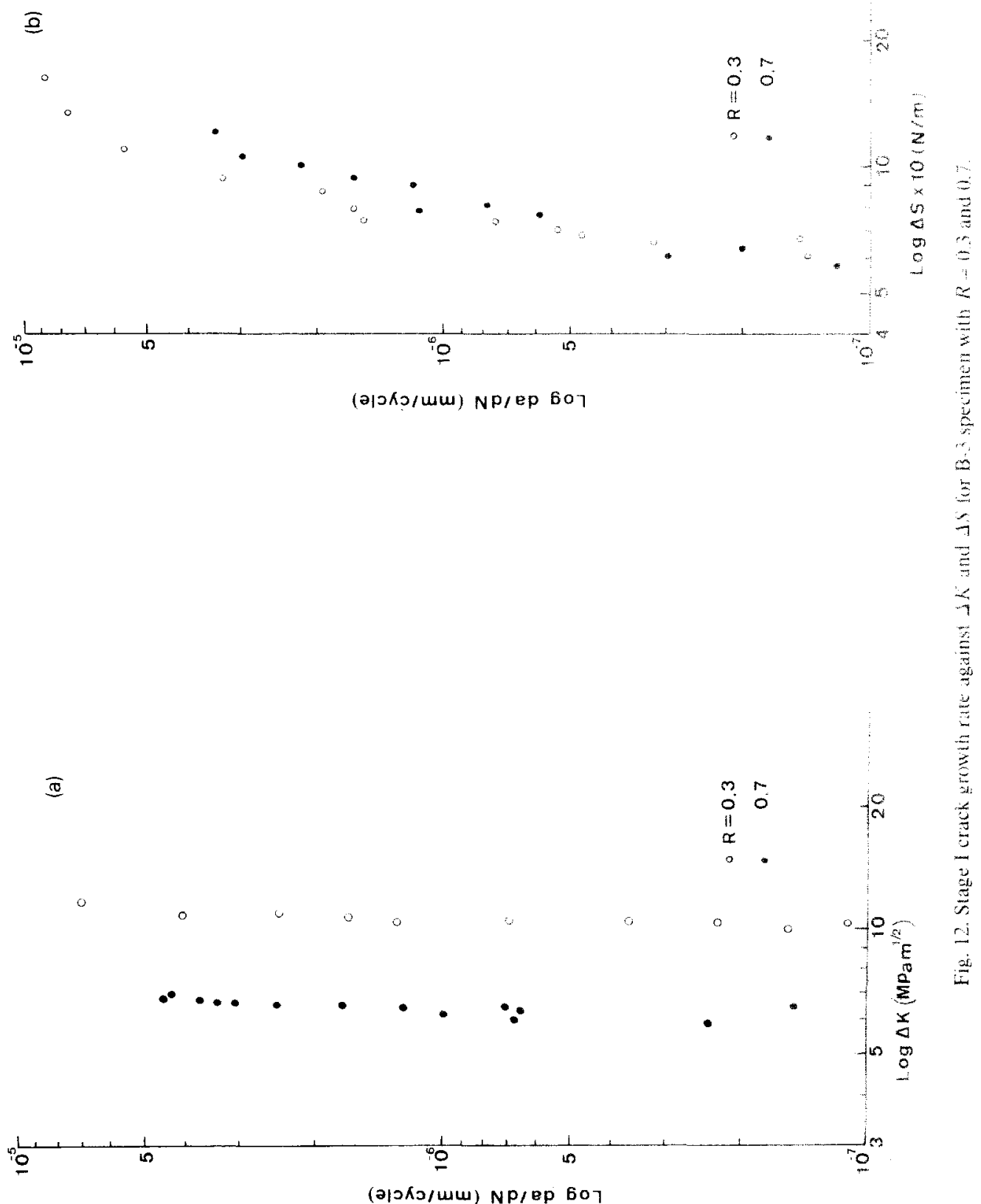




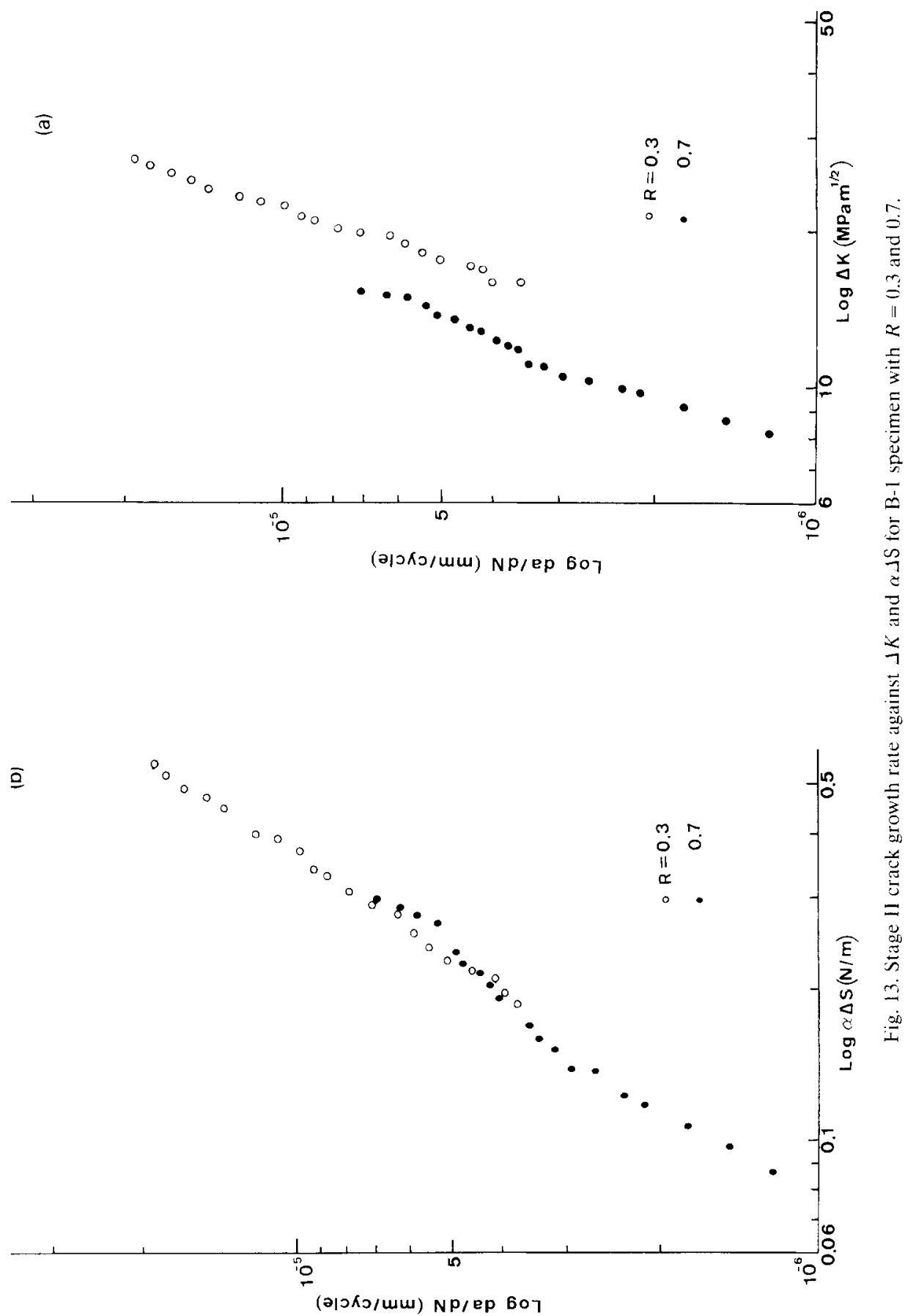




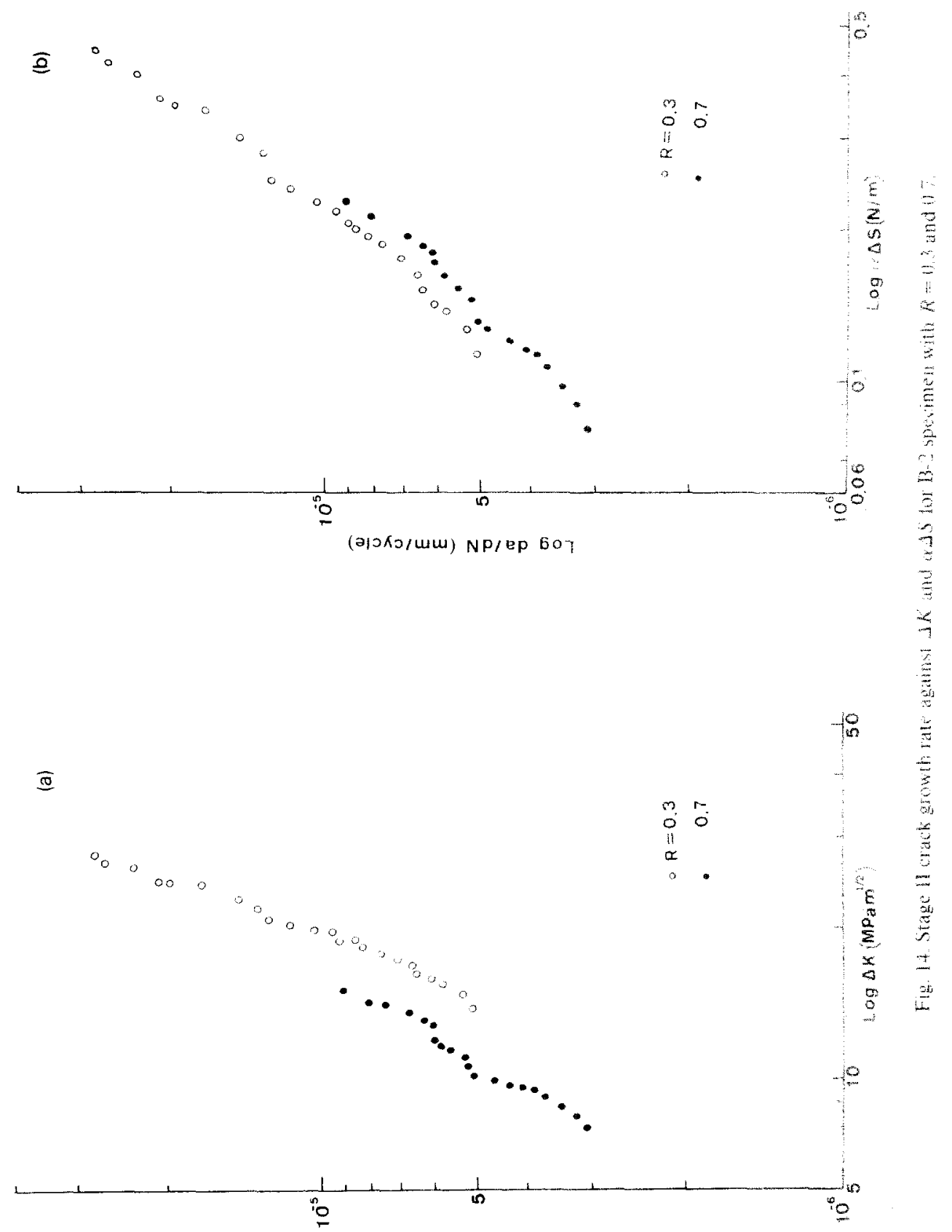

(गכКว/Uس) NP/Ep 607 

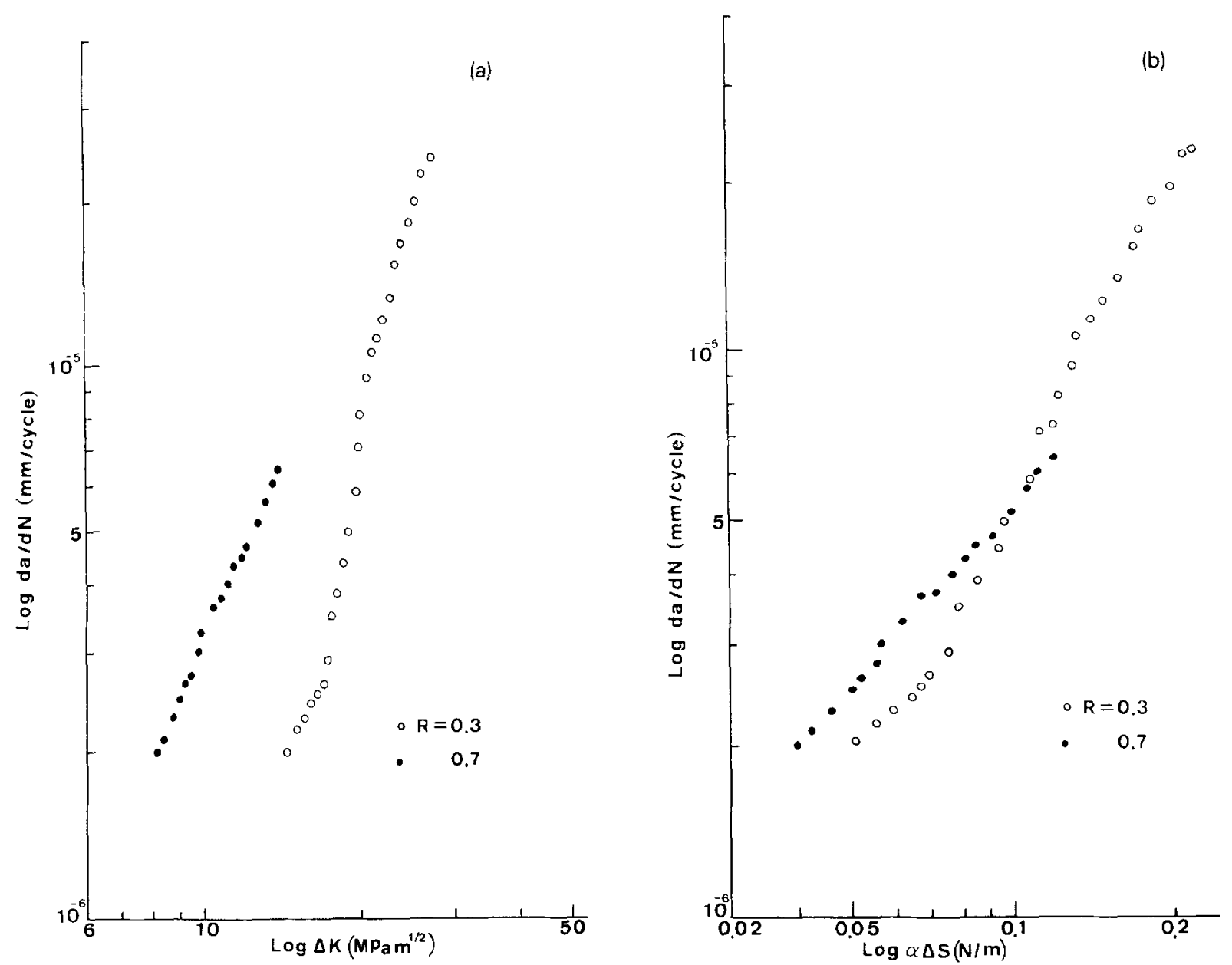

Fig. 15. Stage II crack growth rate against $\Delta K$ and $\alpha \Delta S$ for B-3 specimen with $R=0.3$ and 0.7 .

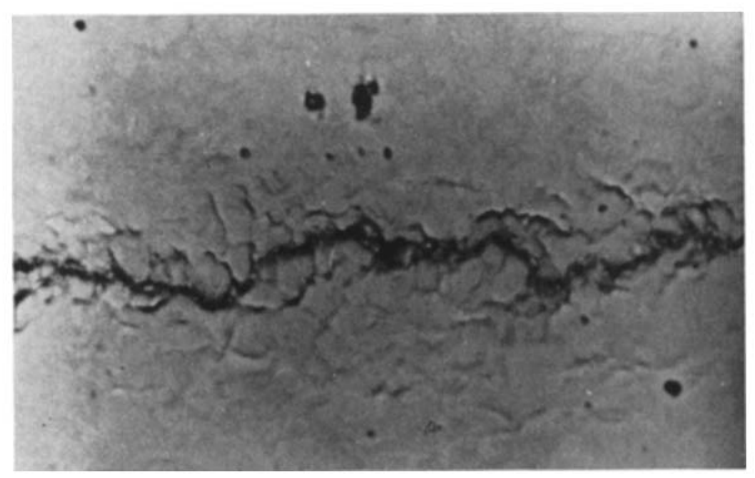

Fig. 16. Microcracks emanating from both sides of main crack $(300 \times)$.
Table 6

Distortion factor measuring ductility of FMDP steel

\begin{tabular}{|c|c|c|c|c|}
\hline \multirow[t]{2}{*}{$\begin{array}{l}\text { Specimen } \\
\text { type }\end{array}$} & \multicolumn{2}{|c|}{$\begin{array}{l}\Omega_{\text {th }} \\
\text { (threshold) }\end{array}$} & \multicolumn{2}{|c|}{$\begin{array}{l}\Omega \\
\text { (Stage II) }\end{array}$} \\
\hline & $R=0.3$ & $R=0.7$ & $\bar{R}=0.3$ & $R=0.7$ \\
\hline$A-1$ & 0.0502 & - & 0.0450 & - \\
\hline A-2 & 0.0284 & - & 0.0109 & - \\
\hline A-3 & 0.0153 & - & 0.0088 & - \\
\hline B-1 & 0.0307 & 0.0060 & 0.0077 & 0.0032 \\
\hline B-2 & 0.0305 & 0.0058 & 0.0078 & 0.0031 \\
\hline B-3 & 0.0310 & 0.0062 & 0.0084 & 0.0034 \\
\hline
\end{tabular}




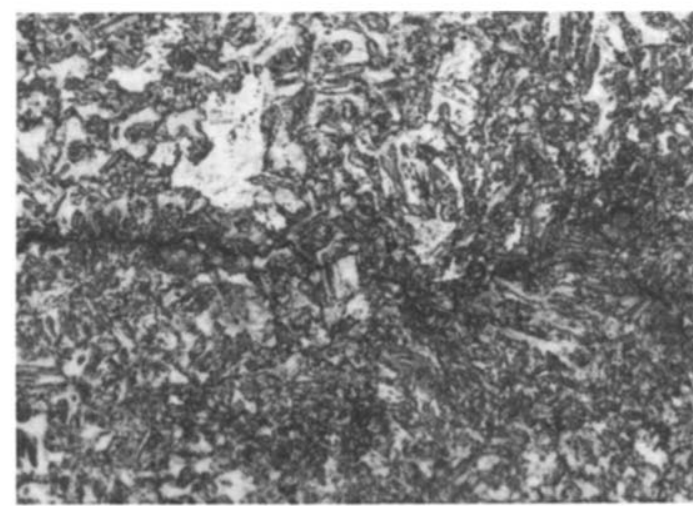

Fig. 17. Crack propagation path $(400 \times)$.

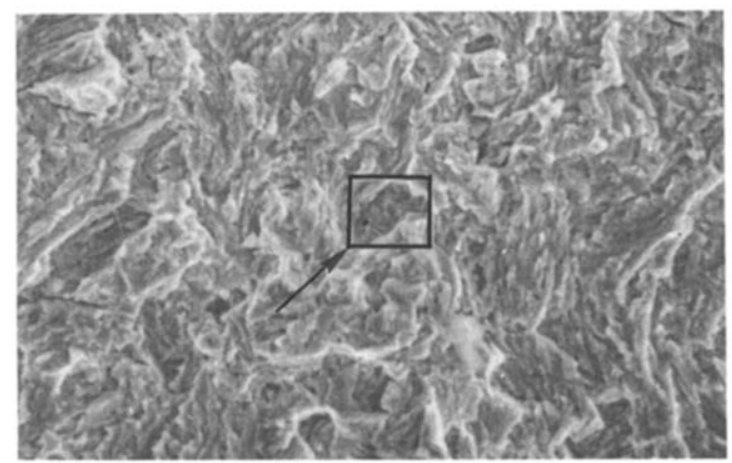

Fig. 18. Fracture morphology near threshold: quasi-cleavage and cleavage $(800 \times)$.

\section{Acknowledgements}

This work was sponsored by the National Nature Science Foundation in the People's Republic of China.

\section{References}

[1] M.S. Rashid, GM980 X-A unique high strength sheet steel with superior formability, SAE Trans. 85 (1976) 938-949.

[2] R.G. Davies, The deformation behavior of a vanadiumstrengthened dual phase steel, Metall. Trans. $7 A$ (1978) $41-52$.

[3] H. Suzuki and A.J. McEvily, Microstructural effects on fatigue crack growth in a low carbon steel. Metall. Tram: 10A (1979) $475-484$

[4] T. Ishchara, Microstructural eftect of fatigue crack growth in a two-phase steel, I Mater Sci 18 (1983) $103-108$.

[5] G.C. Sih and B. Barthelemy, Mixed mode fatigue crack growth predictions, Int. I. Eng. Fract Mech. 13 (1980) $439-451$

[6] G.C. Sih. Fracture mechanics of engineering structurat components, in Fracture Mechanics Technology, edited by G.C. Sih and L. Faria (Martinus Nijhoff: Dordrecht, The Netherlands, 1984) pp. 35-101.

[7] R. Badaliance, Application of stritin energy density lactor to fatigue crack growth analysic, hnt J. Eng. Fract. Mech. $13(1980)(3)$.

[8] R. Badaliance, A fatigue crack growth theory based on strain energy density, Proc Sympositum on Absorbed Spe. afic Energy Strain Energy Density edited by G.C. Sih, F. Czoboly and F. Gillemot, Budapest, Hungary. September 1980.

[9] R.Y. Deng and Y.F. Ma, Fatigue crack propagation near threshold in $15 \mathrm{MnVN}$ steel. Mechanical Strength $1(1982)$ $22-28$.

[10] R.Y. Deng and A.H. Zhou, Slow propagation of fatigue crack near threshold, Acta Metall. Sinica $2 A$ (6) (1989) $439-443$.

[11] V.B. Dutta, S. Suresh and R.O. Ritchie, Fatigue crack propagation in dual-phase steels: effects of ferritemartensitic microstructures on erack path morphology. Metall. Trans. 15A (1984) 1193-1202.

[12] G.T. Gray, IlI, J.C. Williams and A.W. Thompson. Roughness-induced crack closure: in explanation for microstructurally sensitive fatigue arck growth, Metall. Trans. IAA (1983) 421-431.

[13] W.W. Gerberich, W. Yu and K. Esaklul, Fatigue theshold studies in $\mathrm{Fe}, \mathrm{Fe}-\mathrm{Si}$ and HSLA steel: part 1 . Effect of strength and surface asperities on closure, Merall. Trans. 154 (1984) 875-888.

[14] S.Suresh, G.F. Zamiski and R.O. Ritche, Oxide-induced crack closure: an explanation for sicar threshold corrosion fatigue crack growth behavior. Metall. Trans 131 (1981) $1435-1443$

[15] S. Suresh and R.O. Ritchic. A geometric model for fatigue crack closure induced by fracture surface roughness, Metall. Trans. 13A (1982) 1627-163]

[16] R.Y. Deng, G.Q. Yu and H. Li, Effect of grain size on slow fatigue crack propagation and plastic deformation near crack tip, Theoret. Appl. Fract. Mech. 7 (1) (1987) $37-40$.

[17] G.C. Sih and D.Y. Jeong, Fatigue and load sequence effect ranked by critical available energy density, Theorer. Appl. Fract. Mech. 14 (2) (1990) 141-151. 